\title{
POISONING CASES OF NOXIOUS SUBSTANCES EATEN AS FOOD: A RETROSPECTIVE STUDY AT A TEACHING HOSPITAL IN MALAYSIA
}

\author{
Xi Kei Fong ${ }^{1}$, Chia Wei Phan ${ }^{1,2,3}$, Noorasyikin Shamsuddin ${ }^{4}$, Liyana Mazni Zulkiflí, Yee Shin Tan $^{3,6}$ and \\ Vikineswary Sabaratnam ${ }^{3,6}$ \\ ${ }^{1}$ Department of Pharmaceutical Life Sciences, Faculty of Pharmacy, Universiti Malaya, 50603 Kuala \\ Lumpur, Malaysia \\ ${ }^{2}$ Clinical Investigation Centre (CIC), 5th Floor, East Tower, University Malaya Medical Centre (UMMC), \\ 59100 Lembah Pantai, Kuala Lumpur, Malaysia \\ ${ }^{3}$ Mushroom Research Centre, Universiti Malaya, 50603 Kuala Lumpur, Malaysia \\ ${ }^{4}$ Department of Clinical Pharmacy \& Pharmacy Practice, Faculty of Pharmacy, Universiti Malaya, 50603 \\ Kuala Lumpur, Malaysia \\ ${ }^{5}$ Department of Emergency Medicine, University Malaya Medical Centre (UMMC), 59100 Lembah Pantai, \\ Kuala Lumpur, Malaysia \\ 6Institute of Biological Sciences, Faculty of Science, Universiti Malaya, 50603 Kuala Lumpur, Malaysia
}

Corresponding author: Chia Wei Phan

Email: phancw@um.edu.my

\begin{abstract}
There is limited information regarding epidemiology of food poisoning in Malaysia as the issue of food poisoning is often perceived as not as huge as compared to other poisoning cases like intoxication by drugs and chemicals. Patients who experience severe food poisoning require hospitalisation, aggressive hydration, and some even require antibiotic treatment. In this study, we aimed to determine an overview of food poisoning cases reported in UMMC. A 10-year retrospective study on the poisoning of other noxious substances eaten as food (ICD10: T62.0-T62.9) in University of Malaya Medical Centre (UMMC) was performed. A total of 23 medical records of patients, admitted from January 2009 to December 2019 were reviewed. The greatest proportion of food poisoning occurred between the ages of 0 and 9 years, with predominance of the male gender. Malay patients accounted for most food poisoning cases. All cases of poisoning, including a mushroom poisoning case (T62.0), were accidental. The mushroom poisoning case was then carefully reviewed. To conclude, this study revealed that the most common cause involved in poisoning was unspecified food poisoning, followed by ingestion of poisonous mushroom. Most patients were given symptomatic and supportive treatments. All patients had favourable outcome and were discharged with full recovery.
\end{abstract}

Keywords: food poisoning, mushroom, noxious substance, toxicology, case study; retrospective; Chlorophyllum molybdites

\section{INTRODUCTION}

Poisoning is a public health problem that causes a major portion of emergency department admissions and may cause serious consequences to health. ${ }^{1}$ Food poisoning occurs as the results of ingestion of food or water contaminated with microorganisms, poisonous chemicals, toxic mushrooms, poisonous plants, or other noxious substances. ${ }^{2-4}$ Food poisoning cases are not rare in Malaysia because the hot and humid climate of this country is very suitable for the growth of the foodborne bacteria. ${ }^{5}$ Statistics published by the Food Safety and Quality Division, Ministry of Health Malaysia showed an increase in food poisoning cases over the past few years with 5,017 cases in 2013, 5,208 cases reported in $2014,5,678$ cases in 2015, as well as a total of 6,012 cases in 2016. ${ }^{6}$ In 2018, there were 15,023 food poisoning cases reported in Malaysia. $^{7}$ Symptoms of food poisoning vary widely, including abdominal pain, vomiting, diarrhoea, and headache depending on the etiological agents. ${ }^{4,8-9}$
Mushroom poisoning, on the other hand, has been known for millennia and is implicated in the death of several historical figures such as the Roman Emperor Claudius. ${ }^{10}$ Among the estimated 5,000 existing mushroom species, there are 200-300 safe and edible mushrooms, while 50-100 mushrooms are known as poisonous. ${ }^{11}$ Moreover, many species of mushrooms have not been determined for their toxicity profile. ${ }^{12}$ The event of mushroom poisoning is different all around the world, depending on local traditions, lifestyle, nutritional factors, climate, and the occurrence of wild mushrooms. ${ }^{13-15}$ Most of the mushroom poisonings' signs and symptoms are mild to moderate gastrointestinal manifestations; such as nausea, vomiting, and diarrhoea. ${ }^{16} \mathrm{It}$ can even lead to organ failure or death. ${ }^{17}$ The most reported species that contribute to mushroom poisoning include Microporous spp., Lepiota cristata, Amanita spp., and Coprinus spp. ${ }^{18}$

Patient's history and initial symptoms are important in diagnosis. It is crucial to obtain specimens of ingested food if possible as 
treatment is highly dependent on the causative species. ${ }^{19}$ Most food poisonings are mild, and patients improve without any specific treatment. Patients who experience severe food poisoning require hospitalisation, aggressive hydration, and antibiotic treatment. ${ }^{8}$ Therapeutic strategies for food poisoning including mushroom are usually symptomatic treatments and supportive care such as hydration, electrolytes replacement, and gastrointestinal decontamination with activated charcoal. ${ }^{11,20}$ For patients with acute liver failure, liver transplantation can be beneficial and lifesaving. ${ }^{21}$

Till now, the knowledge gap still exists as there is limited information regarding epidemiology and management of food poisoning in Malaysia. As seen in a global perspective, food poisoning is not as huge compared to other poisoning cases, for instance intoxication by drugs and chemicals. The aim of the study was to review the poisoning cases on the toxic effect of other noxious substances eaten as food in University Malaya Medical Centre (UMMC) teaching hospital through a 10-year retrospective analysis. We described the demographic characteristics, clinical manifestations, as well as clinical managements of food poisoning of patients included in the study. We also reviewed a mushroom poisoning case reported in our hospital, specifically the information on clinical features, management, and final treatment outcome of the patient.

\section{METHODS}

Design and setting of the study

This is an observational study where data were collected retrospectively. The study was conducted in UMMC, which is a teaching and tertiary education hospital in Kuala Lumpur. Poisoning cases caused by ingestion of other noxious substances as food from January 2009 to December 2019 were included in the study. Using the hospital patient information system (iPESAKIT) of UMMC, patient's record which met the principle of International Classification of Disease, Tenth Edition (ICD-10) system for "other noxious substances eaten as food" which is T62 (T62.0-T62.9) were identified.

- T62.0: Toxic effect of ingested mushrooms

- T62.1: Toxic effect of ingested berries

- T62.2: Toxic effect of other ingested (parts of) plant(s)

- T62.8: Toxic effect of other specified noxious substances eaten as food.
- T62.9: Toxic effect of unspecified noxious substance eaten as food.

The medical records for all the eligible subjects were traced and retrieved from the Medical Record Unit by using the patient's registration number. In addition, a mushroom poisoning case in UMMC coded under ICD-10 T62.0 was reported in the study. The study was approved by the UMMC Medical Ethics Committee (MRECID No: 201910317970).

\section{Patients and Medical Records}

Cases were included in the study if they fulfilled the following criteria. Inclusion criteria: All poisoning cases that were coded under ICD-10 (T62.0-T62.9) and admitted to UMMC from January 2009 to December 2019. T62 is the ICD-10 code for the diagnosis of "Toxic effect of other noxious substances eaten as food". Exclusion criteria: Patients who were recorded with the wrong ICD-10 code were excluded from the study.

\section{Data Collection}

Relevant data for the study was collected and extracted from the patients' medical records by using a data collection form. Data collection form was prepared to gather all data that was needed in this study. General information or demographics that include patients' age, gender, ethnicity, and marital status were included in the form. Data on patient profile, circumstances of poisoning, clinical symptoms, hospitalisation days, clinical management, and final treatment outcome were extracted and analysed.

\section{Data Analysis}

Microsoft Excel 2010 was used to perform descriptive analysis of the data. The results were presented and tabulated with frequency $(\mathrm{n})$ and percentage $(\%)$ for categorical variables and with mean \pm standard deviation for continuous variables. Appropriate graphs and tables were used to present the data.

\section{RESULTS}

\section{Patient disposition}

There was a total of 38 poisoning cases coded under ICD-10 (T62) reported in UMMC from January 2009 to December 2019. Application was done to retrieve patient's medical records from the Medical Record Unit. Fifteen subjects were then excluded after screening of inclusion and exclusion criteria. Therefore, 23 subjects who met the inclusion criteria were included as the final number of eligible patients. The flow diagram of patient disposition is shown in Figure 1. 


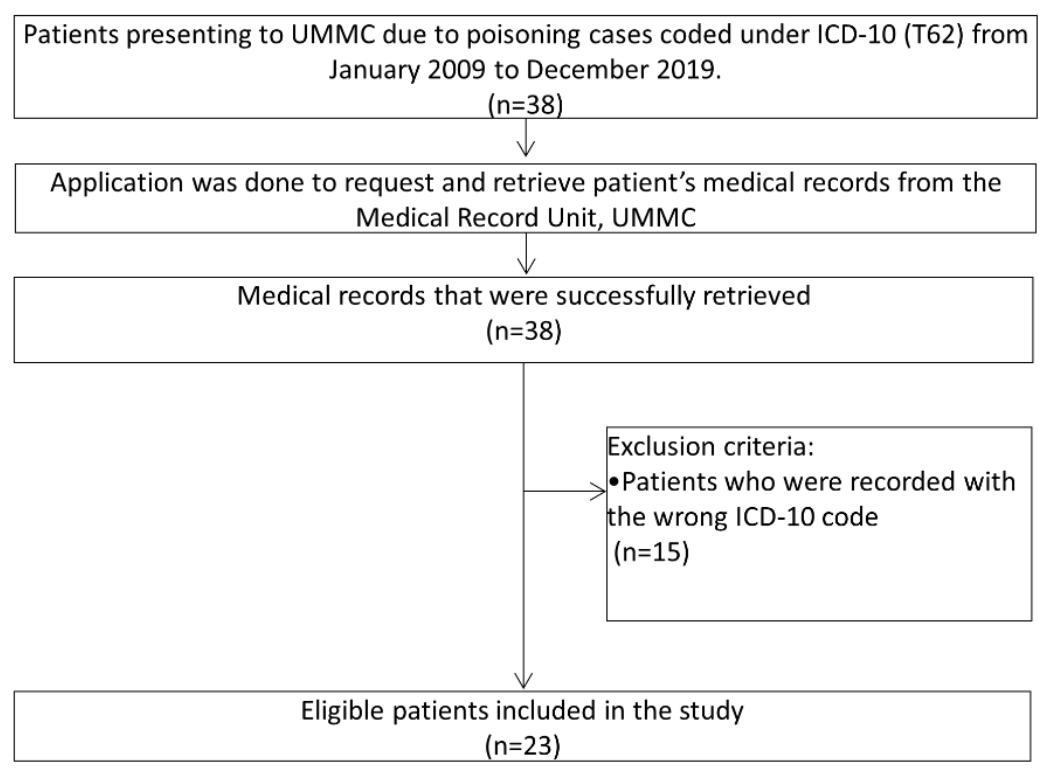

Figure 1. Flow diagram of patient disposition in retrospective analysis from January 2009 to December 2019.

Trend of poisoning case of other noxious substances eaten as food in UMMC

Based on the 10-year retrospective analysis, there were a total of 23 actual medical records coded under ICD-10 (T62) retrieved after screening of inclusion and exclusion criteria. The annual and accumulated number of poisoning cases of other noxious substances eaten as food from January
2009 to December 2019 is shown in Figure 2. There was a fluctuation in terms of the annual number of poisoning cases of other noxious substances eaten as food. The annual number of poisoning cases over the 10-year retrospective study period ranged from 0 to 8 patients, with a peak in 2011.

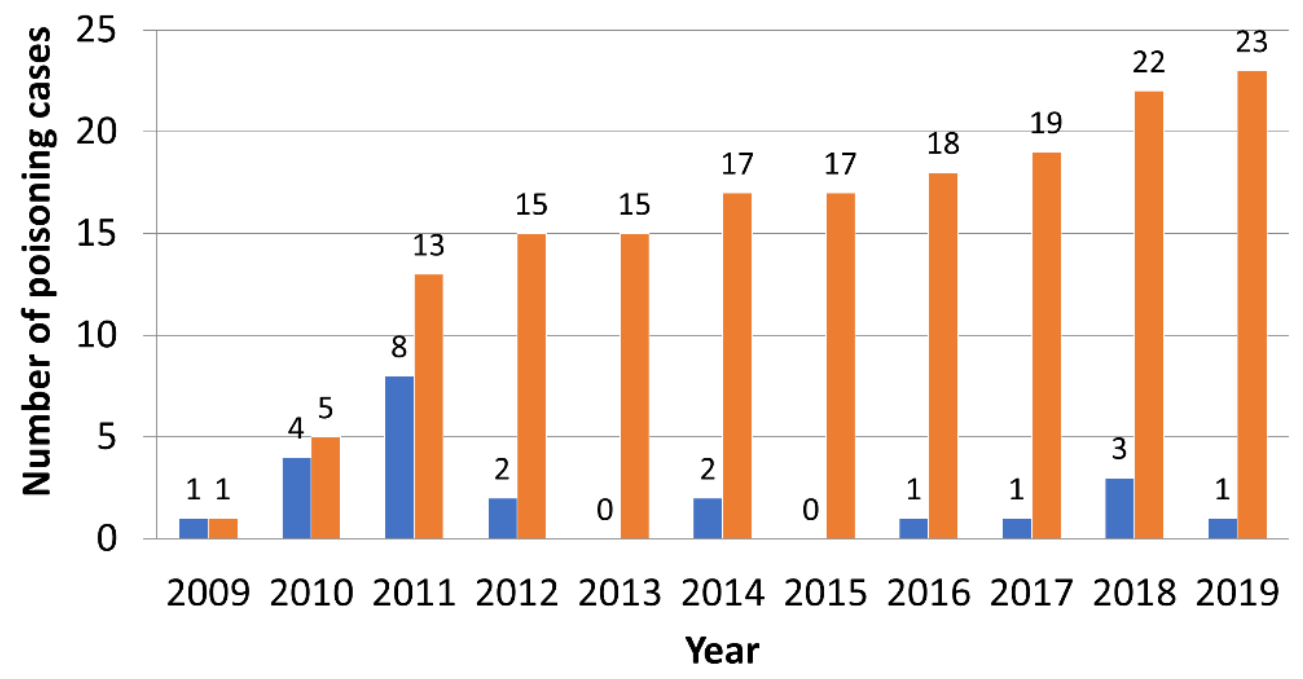

Number of poisoning cases

Accumulated number of poisoning cases

Figure 2. Annual (blue) and accumulated (orange) number of poisoning cases of other noxious substances eaten as food from 2009 to 2019. 
Demographic and clinical characteristics of patients

The details of the characteristics of patients admitted to UMMC from January 2009 to December 2019 due to food poisoning are presented in Table I. Of the 23 total patients admitted to UMMC during the study, there were a slightly higher proportion of male patients compared to female patients in the amount of poisoning cases reported in UMMC. Of them, 14 $(60.9 \%)$ were male and 9 (39.1\%) were female. The mean $( \pm S D)$ age of the study population was $16.5 \pm 15.8$ years (median 14 years), with a range from 1-59 years. The predominant age range was at the age of $0-9$ in 9 patients $(39.1 \%)$, followed by 6 patients $(26.1 \%)$ with $10-19$ years of age as shown in Table I. This indicates that most poisoning cases occur among children. Malay patients accounted for most of the poisoning cases in UMMC which were 14 patients (60.9\%), followed by Indian (21.7\%), Chinese (13.0\%) and patients with other groups of ethnicities (4.3\%). All patients admitted to UMMC from January 2009 to December 2019 due to ingestion of other noxious substances as food are living in urban areas $(100 \%)$. All poisoning cases $(100 \%)$ were caused by accidental ingestion of other noxious substances as food. Majority of the poisoning admissions occurred due to ingestion of unspecified noxious substances as food (T62.9, $95.7 \%$ ), followed by a case of mushroom poisoning (T62.0, 4.3\%) reported to UMMC from January 2009 to December 2019. It is noteworthy to mention that the patients were seen as outpatient or in the Emergency Department, indicating the severity of the food poisoning illness.

Table I. Characteristics of patients admitted to UMMC from January 2009 to December 2019 due to poisoning

\begin{tabular}{lll}
\hline Characteristics & Frequency (n) & Percentage (\%)
\end{tabular}

\section{Gender}

Female

Male

Age

0-9

60 and above

Ethnic

Indian

Chinese

Malay

Others

\section{Residence}


Table I. Continue Intent of injury

Unintentional

Intentional

Source of poison (ICD-10, T62)

Mushroom (T62.0)

Noxious substances eaten as food, unspecified (T62.9)

\section{Signs and symptoms of poisoning} Majority of the patients were presented to the Emergency Department with gastrointestinal symptoms in the form of nausea, vomiting, diarrhoea, and abdominal pain. Vomiting was present in $82.6 \%$ of the patients, which accounted as the most frequent symptom experienced by the patients, followed by abdominal pain (34.8\%), diarrhoea (30.4\%) and nausea (8.7\%). Subcutaneous involvement in the form of body rashes and swelling were presented in 2 patients $(8.7 \%)$, respectively. Of the 23 patients, 3 patients $(13.0 \%)$ had fever and 2 patients $(8.7 \%)$ experienced headache during the admission to UMMC. No severe clinical outcomes were observed in this group of patients. The signs and symptoms of poisoning experienced by patients admitted to UMMC from January 2009 to December 2019 are shown in Table II.

Table II. Signs and symptoms of poisoning experienced by patients admitted to UMMC from January 2009 to December 2019

\begin{tabular}{lcc}
\hline Systems & Frequency $(\mathrm{n})$ & Percentage (\%) \\
Gastrointestinal & 2 & 8.7 \\
Nausea & 19 & 82.6 \\
Vomiting & 7 & 30.4 \\
Diarrhea & 8 & 34.8 \\
Abdominal pain & & \\
Subcutaneous & 2 & 8.7 \\
Rash & 2 & 8.7 \\
Swelling & & 13.0 \\
Miscellaneous/ others & 3 & 8.7 \\
Fever & 2 & \\
Headache & &
\end{tabular}

\section{Management of poisoning}

The most used treatments in this study were oral rehydration salt $(47.8 \%)$, followed by metoclopramide (Maxolon $\left.^{\circledR}\right)(17.4 \%)$, hyoscine butylbromide (Buscopan $^{\circledR}$ ) (17.4\%), ranitidine $(8.7 \%)$, and corticosteroid (8.7\%). As shown in
Table III, diphenoxylate and atropine (Lomotil ${ }^{\circledR}$ ), antacid, pantoprazole, paracetamol, adrenaline, and cetirizine accounted for $4.3 \%$, respectively. Additionally, IV fluid like dextrose $5 \%$ and normal saline were also favoured (43.5\%), followed by 
milk (8.7\%), and activated charcoal (4.3\%). Figure 3 summarises the treatments carried out for poisoning cases in UMMC. A total of 22 patients (95.7\%) were given symptomatic and supportive treatment, which were the most implemented

Table III. Treatments of poisoning due to other noxious substances ingested as food in UMMC

\begin{tabular}{|c|c|c|}
\hline Treatments & Frequency $(n)$ & Percentage (\%) \\
\hline IV fluid (dextrose $5 \%$ and normal saline) & 10 & 43.5 \\
\hline Milk & 2 & 8.7 \\
\hline Activated charcoal & 1 & 4.3 \\
\hline Oral Rehydration Salt & 11 & 47.8 \\
\hline $\begin{array}{l}\text { Maxolon }{ }^{\circledR} \\
\text { (Metoclopramide) }\end{array}$ & 4 & 17.4 \\
\hline $\begin{array}{l}\text { Buscopan }{ }^{\circledR} \\
\text { (Hyoscine butylbromide) }\end{array}$ & 4 & 17.4 \\
\hline Ranitidine & 2 & 8.7 \\
\hline Corticosteroid & 2 & 8.7 \\
\hline Lomotil $\circledast$ & 1 & 4.3 \\
\hline (Diphenoxylate-Atropine) & & \\
\hline Antacid & 1 & 4.3 \\
\hline Pantoprazole & 1 & 4.3 \\
\hline Paracetamol & 1 & 4.3 \\
\hline Adrenaline & 1 & 4.3 \\
\hline Cetirizine & 1 & 4.3 \\
\hline
\end{tabular}

treatment approach for poisoning cases. It was followed by symptomatic and supportive treatment with activated charcoal (4.3\%). There was no antidote given to the patients. 


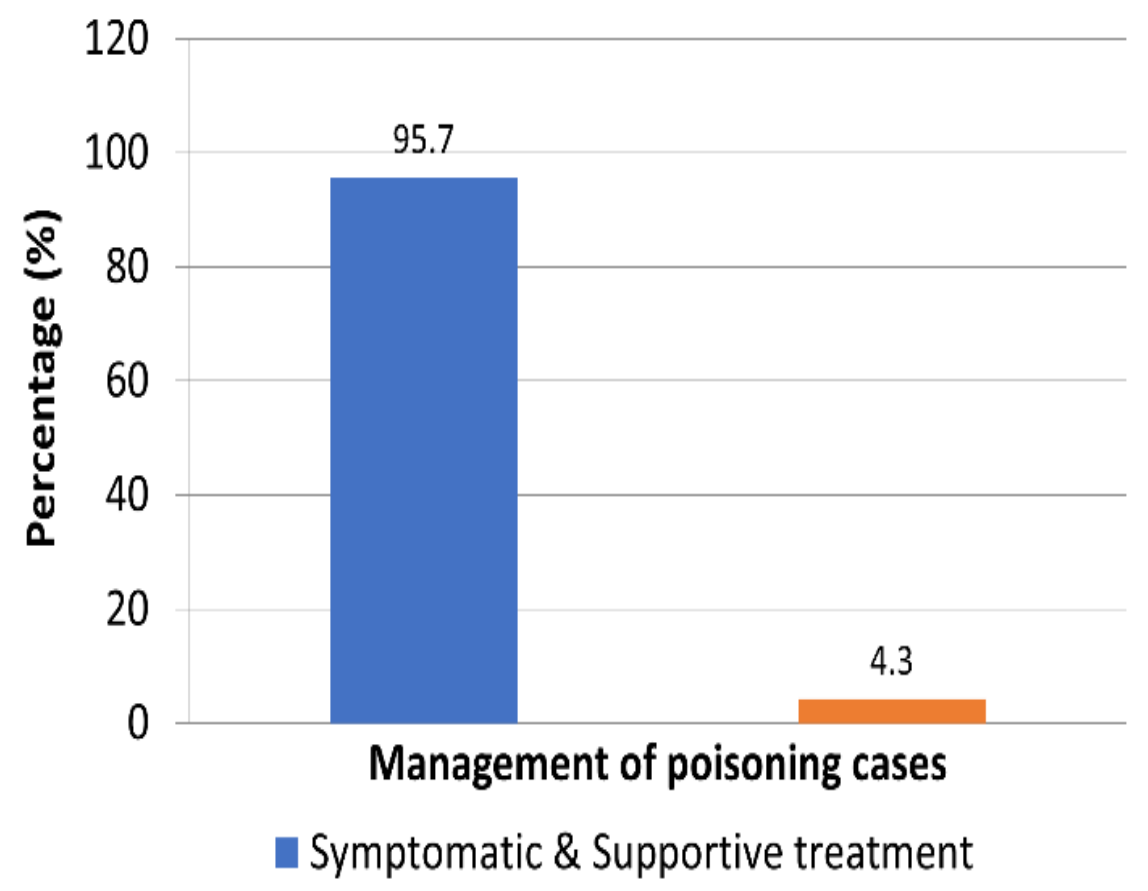

Figure 3. Treatments carried out for poisoning cases in UMMC.

\section{Duration of hospitalisation}

The total admission hours were ranged between 0 and 48 hours, with mean of 18.7 hours. Of the 23 patients, 7 patients $(34.8 \%)$ did not require hospitalisation and were treated at Emergency Department for less than 24 hours while 12 patients (52.2\%) were discharged after 24 hours of hospitalisation at UMMC. Three patients $(13.0 \%)$ were hospitalized for 48 hours to receive treatment. Figure 4 shows the duration of hospitalisation of patients in UMMC due to food poisoning.

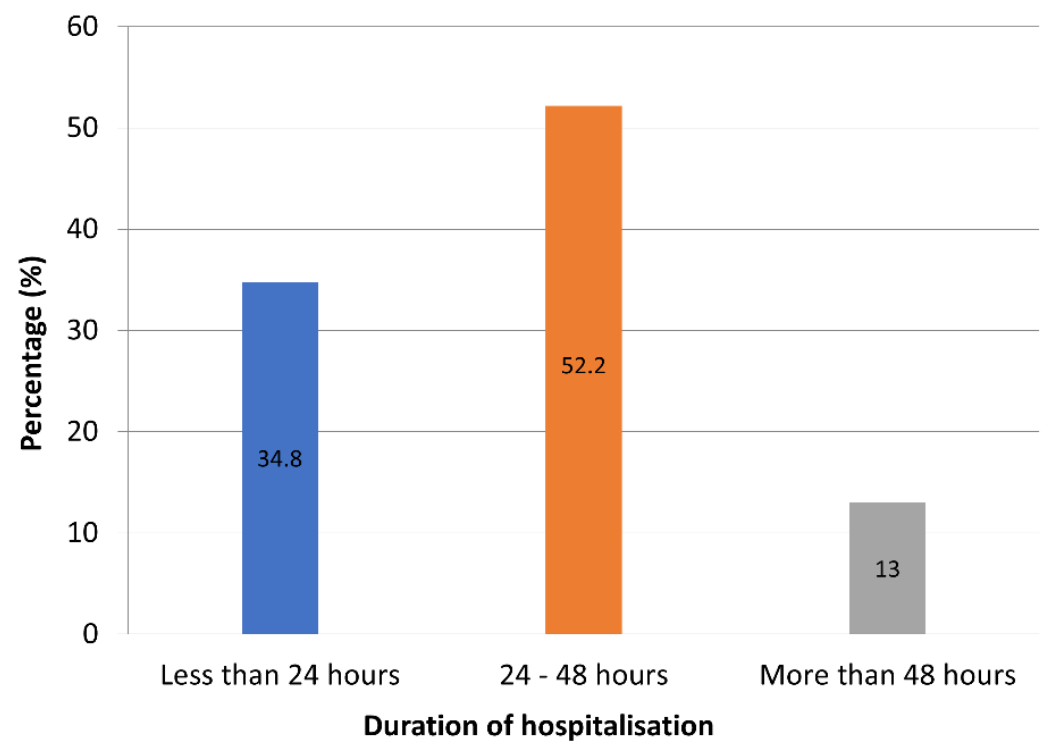

Figure 4. Duration of hospitalisation of patient in UMMC due to ingestion of other noxious substances as food.

\section{Outcome of poisoning case}

All patients $(\mathrm{n}=23)$ involved in poisoning cases in UMMC survived and were discharged from hospital with complete recovery. There were no deaths reported due to ingestion of noxious substances as food.

\section{Mushroom poisoning: Case Report}

There was a mushroom poisoning case reported in UMMC in 2012. An 8-year-old male patient was admitted to the Emergency Department after vomiting up to 10 times with upper abdominal 
pain. The onset was 6 hours after ingestion of one handful size of intake of the cooked wild mushrooms. The mushrooms were collected at Puchong near to his father's workshop by his aunty and were stir fried for dinner. No mushroom sample was provided. As described, the mushroom was about $12 \mathrm{~cm}$ tall, white cap with brown patches and stalk. Based on description, the mushroom is close to the characteristics of the "green-spored parasol", Chlorophyllum molybdites.

The patient had no diarrhoea, no giddiness, but claimed to have some chest pain most likely due to epigastric pain. He had no medical history, no known drug allergies and was not on any medication. His birth history was not recorded due to absence of caretakers around. The patient's father and aunty experienced chest pain, severe vomiting, and drowsiness after ingestion of the same mushrooms. His father had profuse vomiting and severe chest pain while his aunty was drowsy. They have recovered from the symptoms after taking some "anti-allergic" medication at home, claiming what they had was "allergic reaction". The auntie was still drowsy with mild Glasgow coma scale (GCS) score of 13$14 / 15$.
On admission, the 8-year-old male patient was awake, afebrile, and fully oriented. He had tachycardia with high heart rate which was 148 beats per minute but was not tachypnoeic. On physical examination, his vital signs were normal, but he had minimal tenderness on the upper abdomen. Examinations revealed $\mathrm{O}_{2}$ saturation of $100 \%$ on room air, blood pressure of $119 / 70$ $\mathrm{mmHg}$, and a body temperature of $36.8^{\circ} \mathrm{C}$. The patient's oral intake was stopped, and fluid replacement therapy was performed. The patient was rehydrated via intravenous administration with $0.45 \%$ sodium chloride and $5 \%$ dextrose $55 \mathrm{ml}$ per hour for full maintenance. GCS charting was done and recorded. After the patient was well hydrated and has no complaint, the dose was reduced to $0.45 \%$ sodium chloride and $5 \%$ dextrose injection $33 \mathrm{ml}$ per hour for half maintenance. He was then allowed oral administration in ward. On follow-up, the clinical symptoms disappeared, and he had no more vomiting and complaints. The laboratory tests did not indicate organ dysfunction (Table IV). The patient was discharged the next day after admission.

Table IV. Laboratory test results on admission of an 8-year-old male patient who had ingested wild poisonous mushroom

Renal function test
Sodium
Potassium
Chloride
Urea
Creatinine

Liver function test

AST

ALT

Total bilirubin

ALP

GGT

Total protein

Albumin

Calcium

Phosphate

Magnesium

\author{
Complete blood count \\ WBC \\ Haemoglobin \\ Haematocrit \\ Platelets
}

\section{$3.2 \mathrm{mmol} / \mathrm{L}$ \\ $166 \mathrm{mmol} / \mathrm{L}$ \\ $6.5 \mathrm{mmol} / \mathrm{L}$ \\ $50 \mu \mathrm{mol} / \mathrm{L}$}

$$
\begin{gathered}
27.2 \times 10^{9} / \mathrm{L} \\
14.6 \mathrm{~g} / \mathrm{dL} \\
0.40 \mathrm{~L} / \mathrm{L} \\
487 \times 10^{9} / \mathrm{L}
\end{gathered}
$$

\section{Blood gases}

$\begin{array}{cc}\mathrm{pH} & 7.396 \\ \mathrm{pCO}_{2} & 42.3 \mathrm{mmHg} \\ \mathrm{pO}_{2} & 39.1 \mathrm{mmHg} \\ \mathrm{HCO}- & 24.3 \mathrm{mmol} / \mathrm{L} \\ \text { Base excess } & 1.1 \mathrm{mmol} / \mathrm{L}\end{array}$

Coagulation screen

$\begin{array}{cc}\text { PT } & 12.3 \mathrm{~s} \\ \text { aPPT } & 23.9 \mathrm{~s} \\ \text { INR } & 1.2\end{array}$

\section{DISCUSSION}

In the present study, males outnumbered females in the number of poisoning cases reported in UMMC. It is similar to the study of Abd-Elhale \& Abd-Elkari that there was a higher male to female ratio (59 to $41 \%$ ) in unspecified food poisoning cases. ${ }^{22}$ However, the study of Kasilo \& Nhachi showed no significant difference between males and females which indicates that both sexes were at risk of food poisoning. ${ }^{23}$

Based on the results, majority of the poisoning admissions involved young patients from the ages of 0-9 years old. The result is consistent with the previous study of Kasilo \& Nhachi, which found preponderance of the unspecified food poisoning in the 2.1-10 years age group accounting for $79 \%$ of the total recorded cases. ${ }^{23}$ Most poisoning cases 
occur among school going age group. These can be seen from the statistics provided by the Ministry of Health Malaysia. ${ }^{6}$ According to the report, a total of 5,265 food poisoning cases in the school canteens and cafeterias were due to improper handling practices, meals prepared too early and was left uncovered until it was served, and inappropriate cooking temperature, which was equivalent to $43 \%$ of the 12,122 food poisoning cases reported in $2014 .{ }^{6}$ At home, infantile food poisoning may occur due to unhygienic practices. This can be prevented by feeding infants with well processed food, keeping utensil clean, using clean water for the food preparation, and pasteurizing infant food. ${ }^{24}$ There are many routes of exposure to infants and children. The behaviour, termed "hand to mouth", exposes children to many agents of risks. Moreover, the immune systems of young children are still developing. Children who are younger than 5 years old are three times more likely to be hospitalised if they have a Salmonella infection. ${ }^{24}$

Malay patients are more likely to be involved in food poisoning cases than Indians, followed by Chinese and other groups of ethnicities, as reported by the Ministry of Health, Malaysia. ${ }^{25}$ This is due to the fact that the Malay ethnic contributes to $50.1 \%$ share of population of Malaysia. In 2005 and 2006, Malays posed the greatest risk for food poisoning compared to other ethnic groups. The incidence rate among the Malays in 2005 was 27.1 per 100,000 populations, followed by Indian (8.67 per 100,000 populations) and others (4.49 per 100,000 populations). ${ }^{25}$ In 2006, the incidence rate among Malays was 46.9 per 100,000 populations, followed by Indian (8.9 per 100,000 populations) and Chinese (4.73 per 100,000 populations). In a recent study released by the Malaysia National Poison Centre, there were more poisoning exposure calls related to Malay ethnicity (28.4\%), followed by Indian (26.1\%), Chinese (13.5\%) and others. ${ }^{26}$ Furthermore, all patients admitted to UMMC from January 2009 to December 2019 were due to accidental ingestion of other noxious substances as food. Study of Kasilo \& Nhachi showed similar results that majority of poisoning cases were accidental, accounting for $99 \%$ of the total. ${ }^{23}$

In our study, from a clinical aspect, poisoning in most of the patients was not serious. Clinical characteristics of the cases reported by the various patients; vomiting $(82.6 \%)$, abdominal pain (34.8\%), diarrhoea (30.4\%) and nausea (8.7\%) are similar to the common symptoms due to bacterial toxins. This is consistent with the study of Tunik (2007) who reported that episodes of acute gastroenteritis not associated with fever are usually caused by organisms producing toxins. ${ }^{27}$ Patients who experience symptoms of body rashes and facial swelling were suspected to have histamine toxicity resulted from consumption of food, typically fish or cheese. ${ }^{28}$
Activated charcoal is one of the gastrointestinal decontamination methods used to reduce the absorption of a substance ingested within an hour in the gastrointestinal lumen. It has powerful adsorption capacity and is given orally or via gastric tube. ${ }^{29}$ Since the quantity of poison ingested is usually unknown to the medical practitioners, the dose is based on actual patient weight which is $1 \mathrm{~g} / \mathrm{kg} .{ }^{30}$ However, activated charcoal is only effective before the poison is absorbed into the body which is approximately 1 hour within ingestion. ${ }^{2,31}$. Based on the results, the patients were given supportive and symptomatic treatment such as oral rehydration salt and intravenous (IV) normal saline to treat dehydration, and IV Dextrose for energy replenishment when blood sugar level is low. IV Maxolon ${ }^{\circledR}$, which is known as metoclopramide is prescribed to patients to treat nausea and vomiting. Buscopan ${ }^{\circledR}$ tablet helps to relieve patients' abdominal pain while IV Ranitidine is given to decrease gastric production in stomach thus prevent gastrointestinal ulcer. There is not much difference in terms of the management of poisoning for young children, as compared to older children and adults. However, the recommended dose of activated charcoal for children from 1 to 12 years old is 25 to $50 \mathrm{~g}$, whereas the dose for adult is 25 to $100 \mathrm{~g}$. The use of cathartics is also not recommended in young children as the laxative effects may cause fluid and electrolyte imbalance and pose danger to them. ${ }^{32}$

The WHO-commissioned global burden of illness study has provided detailed estimates of the burden of foodborne disease in the WHO SouthEast Asia Region. ${ }^{33,34}$ Malaysia was included in the West Pacific Region-B region, alongside with China, Philippines, Republic of Korea, and Vietnam. Malaysia is considered as a nation that has "low child mortality and very low adult mortality". ${ }^{35}$ Hungary, Kazakhstan, and Lithuania are considered subregions that have "low child mortality and high adult mortality". Meanwhile, Australia, Brunei Darussalam, Japan, New Zealand, and Singapore are categorized as regions having a "very low child and adult mortality' in terms of foodborne illness and poisoning.

Mushroom poisoning is a medical emergency and requires rapid treatment. Immediate, life-saving measures may be needed initially if the mushroom is identified to be toxic. In this case, the patient claimed to have eaten a "white" mushroom, which was morphologically similar to the mushroom bought from grocery store. The patient's aunty described the mushroom as about $12 \mathrm{~cm}$ tall, white cap with brown patches and stalk. Based on the description, the poisonous mushroom is close to the characteristics of the green-spored parasol, Chlorophyllum molybdites. Similar to our study, Palanimuthu et al. had reported a case series of a family (4 members) presenting with Chlorophyllum molybdites 
mushroom poisoning. The mushroom which has been picked up by the roadside and was mistaken for the edible Termitomyces mushroom, commonly known as "cendawan busut" in the Malay language. ${ }^{36}$ Chlorophyllum molybdites is a common species that grows on grassy area. This mushroom has light brown scales at the top of white cap, white to brownish green gills underneath the cap and the stipe of the mushroom turned reddish brown when bruised. ${ }^{37}$ Management of mushroom poisoning includes symptomatic and supportive treatment, identification of the poison, prevention of further absorption, and toxin removal. ${ }^{38,39}$ To help medical practitioners in the management of mushroom poisoning, the public is advised to eat only a small portion of foraged mushrooms and keep a sample of them. ${ }^{40} \mathrm{~A}$ photo of the mushrooms can be taken before ingestion if possible. This can be used for identification purposes and risk assessment if mushroom poisoning is suspected.

\section{CONCLUSION}

In conclusion, this study has managed to provide an overview of the epidemiology of poisoning due to ingestion of noxious substances as food in UMMC from January 2009 to December 2019. There was a higher prevalence of poisoning in males. Majority of the poisoning admissions involved young patients from the age of 0-9 years old and Malay patients accounted for the most poisoning cases. Unspecified food poisoning was the most common cause of food poisoning followed by mushroom poisoning. Most of the patients were given symptomatic and supportive treatment and all of them were discharged after complete recovery.

Knowing these trends of poisonings will provide a basis for the identification of areas where training, education, and legal interventions may be required. Further, research is necessary to provide more insight into the specific substances that are involved in poisoning. Incorrect ICD-10 coding or miscoding in the assignment of diagnosis is often detected in the study. Therefore, it is recommended to give privilege to the medical coder with frequent exposure to ICD coding training course internal and external at least twice a year to ensure accurate coding in UMMC. UMMC should also carry out regular monitoring of clinical coding quality to prevent any error in the future. In mushroom poisoning cases, accurate recognition of mushroom species is important in avoiding toxicity and enabling successful treatment through the rapid detection of intoxication symptoms, thus alleviates the incidence and mortality. To the best of our knowledge, this would be the first retrospective study on food poisoning in a tertiary education hospital in Malaysia. It is hoped that this study would be useful in helping hospitals to have proper documentation in future and better management of food poisoning, thus providing preventive guidance to reduce the morbidities and mortality of food poisoning.

\section{Conflict of interest}

The authors declare no potential conflict of interest.

\section{Acknowledgements \\ We acknowledge the staffs in the Department of Patient Information, UMMC. We would also like to acknowledge the Universiti Malaya Community and Sustainability Centre (UMCares) for providing the UMCares grants, RU009-2017I and RU014- $2018 \mathrm{~F}$.}

\section{REFERENCES}

1. Uges $D$. What is the definition of a poisoning? J Clin Forensic Med 2001; 8: 30-33.

2. Michael JM, Robert GH. Toxicity of muscimol and ibotenic acid containing mushrooms reported to a regional poison control center from 2002-2016. Clin Toxicol 2019;57: 99 103.

2. Ezat WP, Netty D, Sangaran G. Paper review of factors, surveillance and burden of food borne disease outbreak in Malaysia. Malaysian J Med Health Sci 2013; 13.

4. Abd W, Lani M, Zin W, Abdullah WZW, Chilek TZT, Hassan Z. A review on incidences of foodborne diseases and interventions for $a$ better national food safety system in Malaysia. Malays Appl Biol 2017; 46: 1-7.

5. Abd-Mutalib N A, Syafinaz AN, Sakai $K$, Shirai Y. An overview of foodborne illness and food safety in Malaysia. Int Food Res J 2015;22: 896-901.

6. Ministry of Health Malaysia. 2016. Annual report. Retrieved from http://vlib.moh.gov.my/cms/docu mentstorage/com.tms.cms. docume nt.Document_cfdfa3ab-a0188549ebcfa200-b93847c6/anr-bi-2016.pdf

7. New CY, Ubong A, Premarathne JM, Thung TY, Lee E, Chang WS, Loo YY, Kwan SY, Tan CW, Kuan CH, Son R. Microbiological food safety in Malaysia from the academician's perspective. J Food Sci 2017; 1:183202.

8. Teisl $M$, Roe B. Consumer willingness-to-pay to reduce the 
probability of retail foodborne pathogen contamination. Food Policy 2010; 35(6): 521-530.

9. Pires SM, Vieira AR, Perez E, Danilo LFW, Hald T. Attributing human foodborne illness to food sources and water in Latin America and the Caribbean using data from outbreak investigations. Int J Food Microbiol 2012; 152(3): 129-138.

10. Diaz JH. Amatoxin-containing mushroom poisonings: species, toxidromes, treatments, and outcomes. Wilderness Environ Med 2018; 29(1): 111-118.

11. Berger KJ, Guss DA. Mycotoxins revisited: Part I. J Emerg Med 2005; 28(1): 53-62.

12. Schenk-Jaeger KM, Rauber-Luthy $C$, Bodmer M, Kupferschmidt $\mathrm{H}$, KullakUblick GA, Ceschi A. Mushroom poisoning: a study on circumstances of exposure and patterns of toxicity. Eur J Intern Med 2012; 23(4): e8591.

13. Sergey $G$, Josef $D$, Aristidis $T$, Ramin R. Poisoning associated with the use of mushrooms: a review of the global pattern and main characteristics. Food Chem Toxicol 2019;128: 267-279.

14. Soltaninejad K. Outbreak of mushroom poisoning in Iran: AprilMay, 2018. Int J Occup Environ Med 2018;9(3): 152-156.

15. Jo WS, Hossain MA, Park SC. Toxicological profiles of poisonous, edible, and medicinal mushrooms. Mycobiology 2014;42(3): 215-220.

16. Eren SH, Demirel $\mathrm{Y}$, Ugurlu $\mathrm{S}$, Korkmaz I, Aktas C, Güven FMK. Mushroom poisoning: retrospective analysis of 294 cases. Clinics 2010; 65:491-496.

17. Keller SA, Jolanta KR. Mushroom poisoning- a 17-year retrospective study at a level I university emergency department in Switzerland. Int J Environ Res Public Health 2018; 15(12):2855.

18. Ukwuru M, Muritala A, Eze LU. Edible and non-edible wild mushrooms: nutrition, toxicity and strategies for recognition. J Clin Nutr Metab 2018; 2(2): 9.
19. Jan MA, Siddiqui TS, Ahmed N, UI Haq I, Khan Z. Mushroom poisoning in children: clinical presentation and outcome. J Ayub Med Coll Abbottabad 2008; 20(2): 99-101.

20. Khatir IG, Hosseininejad SM, Ghasempouri SK, Asadollahpoor A, Moradi S, Jahanian F. Demographic and epidemiologic evaluation of mushroom poisoning: a retrospective study in 4-year admissions of Razi Hospital (Qaemshahr, Mazandaran, Iran). Med Glas (Zenica) 2020; 17(1):117122.

21. Broussard CN, Aggarwal A, Lacey SR, Post AB, Gramlich T, Henderson JM, Younossi ZM. Mushroom poisoning-from diarrhea to liver transplantation. Am J Gastroenterol 2001;96(11): 3195-3198.

22. Abd-Elhale ZA, Abd-Elkari MA. Pattern of food poisoning in Egypt, a retrospective study. Am J Pharmacol Toxicol 2011;6: 505-515.

23. Kasilo OM, Nhachi CF. Food poisoning admissions in referral hospitals in Zimbabwe: A retrospective study. Hum Exp Toxicol 1994;13(2): 77-82.

24. Okoronkwo CU. Food poisoning of the infantile group, microbiological standpoint. J Food Nutrition and Population Health 2020; 4(4):18.

25. Tangiisuran $B$, Jiva $M$, Ariff $A M$, Abdul Rani NA, Misnan A, Rashid SM, Majid MIA, Dawson AH. Evaluation of types of poisoning exposure calls managed by the Malaysia National Poison Centre (2006-2015): A retrospective review. BMJ Open 2018; 31;8(12):e024162.

26. Ministry of Health Malaysia. 2006. Malaysia's health. Retrieved from https://www.moh.gov.my/moh/im ages/gallery/publications/mh/Mala ysia\%20Health\%202006-2.pdf

27. Tunik MG. Food Poisoning. In: Goldfrank's Manual of Toxicol Emerg. (9th ed.; L. S. Nelson R.S. Hoffman, N.A. Lewin, L.R. Goldfrank, M.A. Howland and N.E. Flomenbaum, Ed.). 2007. New York: McGraw Hill Companies. 
28. Keith AL, Susan MC, Sufian AK. Bad bug book: handbook of foodborne pathogenic, microorganisms and natural toxins. (2nd ed.). 2012. USA: Food and Drug Administration.

29. Chadha I. Poisoning. Indian J Anaesth 2003;47(5): 402.

30. Mokhlesi B, Leiken JB, Murray P, Corbridge TC. Adult toxicology in critical care: part I: general approach to the intoxicated patient. CHEST 2003;123(2): 577-592.

31. Al-Haidari KM. General Management of Poisoned Patients. In: Elzouki AY, Harfi HA, Nazer HM, Stapleton FB, Oh W, Whitley RJ (eds) Textbook of Clinical Pediatrics. 2012. Springer, Berlin, Heidelberg.

32. Ministry of Health, Singapore. $\mathrm{MOH}$ Clinical Practice Guidelines, December 2011. Available from: http: / /www.moh.gov.sg/cpg (accessed 24 June 2021)

33. On SLW, Rahayu, WP. Estimates for the burden and costs of foodborne diarrhoeal illness in Indonesia. AsiaPacific J Food Safety and Security 2017; 3(1):3-16.

34. World WHO [World Health Organisation]. WHO estimates of the global burden of food-borne diseases. World Health Organisation (Publishers) 2016, ISBN 978924 1565165.

35. Ezzati M, Lopez AD, Rodgers A, Vander Hoorn S, Murray CJ.
Comparative Risk Assessment Collaborating Group. Selected major risk factors and global and regional burden of disease. Lancet 2002; 360(9343):1347-1360.

36. Palanimuthu B, Idrose A, Sabaratnam V. OP 2 "Tempting mushroom with deadly bites - dinner that almost kill my family"-case series of Chlorophyllum molybdites mushroom poisoning. Malaysian J Emergency Med 2016;1(2): Supplementary Issue 1-2.

37. Phyllis H. Stenklyft, W. Lynn Augenstein. Chlorophyllum molybdites-severe mushroom poisoning in a child. Clin Toxicol 1990; 28(2): 159-168.

38. Pajoumand A, Shadnia S, Efricheh $\mathrm{H}$, Mandgary A, Hassanian-Moghaddam $\mathrm{H}$, Abdollahi M. A retrospective study of mushroom poisoning in Iran. Hum Exp Toxicol 2006; 24: 609-613.

39. Köppel C. Clinical symptomatology and management of mushroom poisoning. Toxicon 1993; 31(12):1513-40.

40. Jonathan De Olano, Josh J. Wang, Eric Villeneuve, Sophie Gosselin, Rana Biary, Mark K. Su, Robert S. Hoffman. Current fatality rate of suspected cyclopeptide mushroom poisoning in the United States. 2020. Clin Toxicol. DOI: 10.1080/15563650.2020.1747624 